\title{
Propagation of Drought: From Meteorological Drought to Agricultural and Hydrological Drought
}

\author{
Wen Wang, ${ }^{1}$ Maurits W. Ertsen, ${ }^{2}$ Mark D. Svoboda, ${ }^{3}$ and Mohsin Hafeez ${ }^{4}$ \\ ${ }^{1}$ State Key Laboratory of Hydrology-Water Resources and Hydraulic Engineering, Hohai University, Nanjing 210098, China \\ ${ }^{2}$ Department of Water Resources Management, Delft University of Technology, 2628 CN Delft, Netherlands \\ ${ }^{3}$ National Drought Mitigation Center, University of Nebraska-Lincoln, 815 Hardin Hall, Lincoln, NE 68583-0988, USA \\ ${ }^{4}$ Water Resources Modelling Unit, Bureau of Meteorology, Brisbane, QLD 4000, Australia
}

Correspondence should be addressed to Wen Wang; w.wang@126.com

Received 4 January 2016; Accepted 11 January 2016

Copyright (C) 2016 Wen Wang et al. This is an open access article distributed under the Creative Commons Attribution License, which permits unrestricted use, distribution, and reproduction in any medium, provided the original work is properly cited.

\section{Drought in the World and China}

Drought is a hazard that occurs everywhere in the world (both in dry and in wet areas). Despite the controversy regarding drought changes in the last decades [1-3], increases in drought intensity are clearly identified in some areas [4] and it is believed that although increased heating from global warming may not directly cause droughts, it is expected that when droughts occur, they are likely to set in quicker and be more intense [5].

Throughout its history, China has frequently suffered from drought disasters due to its monsoon climate and was regularly hit hard by droughts over the last decades. Although little evidence of an expansion of the area affected by droughts was found in China over the last 50 years [6], severe droughts in southwestern China in 2010 and the middle/lower Yangtze Basin and Huaihe River Basin in 2011 have drawn more attention from the research community as well as from the public and governments alike on the impacts and problems brought on by drought. Poor performance by China's emergency response management during recent major drought events highlights the necessity of improving both drought preparedness and emergency response skills.

To improve our skills for drought monitoring and forecasting as a means of reducing society's vulnerability to droughts and the risks they pose, it is important to distinguish between different types of drought, reveal how droughts propagate from one type to another, study the causes of drought, and know how drought affects various economic sectors (e.g., agriculture, energy production, and navigation) and ecosystems in diverse ways. Furthermore, it is vital that we continue to explore and better understand how aggregated human activities affect the process of drought propagation so as to better prepare for and adapt to future drought changes.

\section{From Meteorological Drought to Agricultural/Hydrological Drought}

Drought originates from a deficiency of precipitation over an extended period of time resulting in a water shortage for some activity, group, or environmental sector. It is the result of a complex interplay between (1) natural precipitation deficiencies, or excessive evapotranspiration over varying time periods and different areal extents, and (2) the demands of human and environmental water use that may be exacerbated by inefficiencies in water distribution, planning, and management [7]. To facilitate communication, management, and response, drought often is categorized into four general types [7]: (1) meteorological or climatological, (2) agricultural, (3) hydrological, and (4) socioeconomic. Drought can develop over short periods (weeks or months) or longer periods (seasons, years, or even decades). Different types of droughts have their own specific spatiotemporal characteristics $[8,9]$. Although hydrological drought and agricultural drought start from meteorological droughts, hydrological and agricultural drought indicators cannot be straightforwardly derived from 
meteorological drought indicators [10, 11]. Lack of precipitation combined with higher evaporation rates propagates through the hydrological cycle from a meteorological phenomenon/drought into soil moisture depletion to the point where crops or terrestrial ecosystems are impacted, and eventually into a hydrological phenomenon/drought $[12,13]$.

The development of droughts involves numerous interacting climate processes and various land-atmosphere feedback. In addition, different stores in catchments (providing persistence) lead to potentially complicated propagations of the climate signal into the water system [14]. To fight against drought and mitigate the impacts of major droughts, it is important to distinguish between different types of drought, to understand how drought evolves from one type to another, and to know how human activities influence the cause/linkages of droughts. The study on the topic of drought propagation has been quite a hot issue in the hydrology community over the last decade [8-10, 14-21]. It is found that there is a significant link between meteorological drought and hydrological drought, except for catchments where groundwater storage and snow processes are important [18]. Several common features of drought propagation have been revealed, such as [17]: (a) meteorological droughts evolve collectively into a prolonged hydrological drought (pooling); (b) meteorological droughts are attenuated when storage is high at the start of the event (attenuation); (c) a lag occurs between meteorological, soil moisture, and hydrological drought (lag); and (d) droughts get longer in duration in moving from meteorological to soil moisture to hydrological drought (lengthening).

However, there are still many more mechanisms behind drought propagation that need to be investigated, such as the interaction between surface water and groundwater during the process of drought development, the evapotranspiration of different plant communities in response to droughts, and human (anticipating and response) strategies manipulating these features. On the other hand, while drought mechanism research has certainly moved forward, more progress has been made in the realm of qualitative knowledge rather than quantitatively. Knowing more about the mechanisms quantitatively will provide a stronger basis for monitoring and forecasting hydrological and agricultural droughts.

\section{The Roles of Human Intervention in Drought Propagation}

Human interventions in the water cycle are about manipulating water flows by (groups of) users for different reasons and adapting water availability in time and space and changing the hydrological patterns in their surrounding landscape. Human activities, such as irrigation activities, dam and reservoir operations, and water diversion may significantly alter the propagation process from meteorological to hydrological droughts as well as affecting drought vulnerability [22-25]. Therefore, the impacts of drought could be mitigated by managing water demand through crop management, modifying water allocation rules during times of water scarcity, developing various water resources (such as groundwater recharge and salt water desalination), managing multiple water use, setting up water-trading mechanisms in advance of times of drought or scarcity, and physically redistributing available supplies during times of scarcity [26].

However, while drought is a climatic phenomenon with relatively predictable biophysical repercussions, social perceptions of and responses to drought from the individual through community and up to the state level are highly varied [27]. At the same time, interactions between natural water availability and societal water demand and management are complex, and drought mitigation strategies in some sectors (e.g., agricultural and energy sectors) may increase the vulnerability of other systems (especially ecosystems) [28]. Multiobjective optimization could be helpful for developing drought plans incorporating traditional short-term tactical measures (e.g., facility operation) and long-term or inadvance strategic mitigation measures for drought preparedness [29] while also balancing the drought risks among different sectors at the same time.

\section{Drought Monitoring and Prediction}

At present, droughts are commonly monitored using indices based on data from three primary sources, that is, ground observations such as the Standardized Precipitation Index (SPI) [30], satellite observations such as the global Drought Severity Index (DSI) [31], and Multivariate Standardized Drought Index (MSDI) [32], as well as model simulations [33-35].

Indicators based on any single source of drought information have their limitations. In order to fully characterize drought magnitude, spatial extent, and potential impacts, drought monitoring methods or indicators should be integrated, coupling multiple climate, water, vegetation, and soil parameters, as well as socioeconomic information retrieved from different sources [36]. Many efforts have been put into developing drought indicators jointly using groundbased, satellite-based, and model simulated data. One of the earliest examples of such a composite, or hybrid, approach is found in the operational US Drought Monitor (USDM) [37], which combines several inputs consisting of modelled data, satellite vegetation health indicators, climate-based indices (such as the SPI), impacts, and local expert input from the field. Other examples include the Aggregated Drought Index (ADI), which comprehensively considers all physical forms of drought through variables like precipitation, streamflow, evapotranspiration, reservoir storage, soil moisture content, and snow water content [38]; the Vegetation Drought Response Index (VegDRI) integrates satellite-based observations of vegetation conditions, climate data, and other biophysical information such as land cover/land use type, soil characteristics, and ecological setting [39]; the Combined Drought Indicator combines the Standardized Precipitation Index (SPI), the anomalies of soil moisture, and the anomalies of the fraction of Absorbed Photosynthetically Active Radiation (fAPAR) [40]. However, there is no significantly preferable or universally accepted multivariate drought index so far (nor is that likely to come) and it is difficult to prove 
the superiority of the various multivariate drought indicators because there is no "ground truth" of drought observations for most places that can be used for an exact validation process [41].

Unlike a flood, a drought does not have an obvious start or end. While monitoring has been done for decades, forecasting drought is still in its infancy [42]. As meteorological drought is dominated by precipitation processes, its forecast is fundamentally an issue of medium-to-long range weather forecasting. Hydrological and agricultural droughts are driven by meteorological droughts; therefore their forecasts also heavily depend on weather forecasting. It is common to use atmospheric model outputs to drive hydrological models for making seasonal hydrological drought forecasts $[43,44]$ or estimating future droughts [45]. In knowing that the drought propagation process is complicated, especially when considering human managed interventions such as reservoir operations, diversions, water consumption, and agricultural activities, many more factors should be involved in hydrological and agricultural drought forecasting. Another major challenge for drought forecasting is due to the fact that forecasts are often unreliable on the seasonal timescale and lack specificity, reducing their usefulness for agriculture and other sectors [36].

\section{Highlights in the Special Issue}

In this special issue, a collection of six papers were chosen that cover topics addressing regional drought changes, drought assessment methods, and impacts of human activities and climate change on drought evolution.

$H$. Huang et al. investigated the spatial-temporal variation of the aridity index, which is defined as the ratio of potential evapotranspiration and precipitation, in China during 19602013, and found that the average annual aridity index showed a decreasing trend. J. Vido et al. found that the frequency of 24 droughts occurring in the Tatra National Park in Slovakia has a cyclical pattern with approximately a 30year period. Furthermore, the precipitation shadow of the mountains influences the risk of drought occurrence. L. Zhao et al. found strong correlations between the Standardized Runoff Index (SRI) and Standardized Precipitation Evapotranspiration Index (SPEI) in the Xiangjiang River Basin in southern China, with a stronger correlation in the dry season compared to the wet season. M. Yu et al. proposed a multiscale Composited Drought Index (CDI) by integrating the self-calibrating Palmer Drought Severity Index (scPDSI), the 1- and 3-month Standardized Precipitation and Evapotranspiration Index (SPEI), Z index, and standardized Soil Moisture Index (SMI) using a principle component analysis method for improving the skill of drought monitoring. Y. Liu et al. presented a case study in a semiarid catchment in northern China addressing the impacts of human activities, which shows that human activities significantly amplified both drought duration and severity in that catchment. F. Yuan et al. develop a modelling system for projecting the potential climate change impacts on hydrological drought events in the Weihe River Basin in northern China and show that that basin can expect more severe droughts in the future.

\section{Future Works on Drought Propagation Mechanisms}

Significant progress has been made in the last decade centering around a better understanding of the mechanisms of drought propagation. Future advances are required in order to address the following aspects:

(1) Develop more long-term and reliable series of drought data, and quantitatively assess data uncertainty whether the data are observed through ground networks or satellites or especially through modelled or simulated approaches, so as to avoid any misinterpretation about changes in drought characteristics.

(2) Establish more comprehensive drought monitoring frameworks, which use multiple observation techniques and modelling tools conjunctively to reflect drought-related hydrological and biophysical variables at different spatial-temporal scales, in order to meet the specific needs of different sectors.

(3) Quantitatively describe the water conversion/drought relationship among different existing forms, that is, soil water, snow/ice water, plant water, groundwater, and river water, at multiple spatial and temporal scales in different catchments and geographical settings.

(4) Reveal the interrelationship between the natural hydrological system and the role of humans played in the process of drought development, considering the effects of different management practices dealing with water allocation, water use, land use/land cover planning, and so on, which are based on multidisciplinary inputs from history, archaeology, anthropology, sciences, and engineering.

(5) Develop strategies for reducing society's vulnerability to drought by improving the skills of drought response based on the knowledge of drought propagation.

\section{Acknowledgments}

The research work on drought by Wen Wang is financially supported by Natural Science Foundation of China project "Mechanism of Catchment Hydrological Responses to Meteorological Droughts" (no. 41371050).

\section{Wen Wang \\ Maurits W. Ertsen \\ Mark D. Svoboda \\ Mohsin Hafeez}

\section{References}

[1] J. Sheffield, E. F. Wood, and M. L. Roderick, "Little change in global drought over the past 60 years," Nature, vol. 491, no. 7424, pp. 435-438, 2012. 
[2] A. G. Dai, "Increasing drought under global warming in observations and models," Nature Climate Change, vol. 3, no. 1, pp. 52-58, 2013.

[3] L. Damberg and A. AghaKouchak, "Global trends and patterns of drought from space," Theoretical and Applied Climatology, vol. 117, no. 3-4, pp. 441-448, 2014.

[4] I. Masih, S. Maskey, F. E. F. Mussá, and P. Trambauer, "A review of droughts on the African continent: a geospatial and longterm perspective," Hydrology and Earth System Sciences, vol. 18, no. 9, pp. 3635-3649, 2014.

[5] K. E. Trenberth, A. Dai, G. Van Der Schrier et al., "Global warming and changes in drought," Nature Climate Change, vol. 4, no. 1, pp. 17-22, 2014.

[6] W. Wang, Y. Zhu, R. Xu, and J. Liu, "Drought severity change in China during 1961-2012 indicated by SPI and SPEI," Natural Hazards, vol. 75, no. 3, pp. 2437-2451, 2014.

[7] American Meteorological Society (AMS), Drought, 2013, https://www2.ametsoc.org/ams/index.cfm/about-ams/amsstatements/statements-of-the-ams-in-force/drought/.

[8] E. Peters, G. Bier, H. A. J. van Lanen, and P. J. J. F. Torfs, “Propagation and spatial distribution of drought in a groundwater catchment," Journal of Hydrology, vol. 321, no. 1-4, pp. 257-275, 2006.

[9] L. M. Tallaksen, H. Hisdal, and H. A. J. V. Lanen, "Space-time modelling of catchment scale drought characteristics," Journal of Hydrology, vol. 375, no. 3-4, pp. 363-372, 2009.

[10] E. Peters, P. J. J. F. Torfs, H. A. J. Van Lanen, and G. Bier, “Propagation of drought through groundwater-a new approach using linear reservoir theory," Hydrological Processes, vol. 17, no. 15, pp. 3023-3040, 2003.

[11] N. Wanders, H. A. J. Van Lanen, and A. F. Van Loon, "Indicators for drought characterization on a global scale," WATCH Technical Report 24, 2010.

[12] D. A. Wilhite, Ed., Drought: A Global Assessment, Routledge, London, UK, 2000.

[13] L. M. Tallaksen and H. A. J. Van Lanen, Eds., Hydrological Drought: Processes and Estimation Methods for Streamflow and Groundwater, Elsevier, Amsterdam, Netherlands, 2004.

[14] A. F. Van Loon and G. Laaha, "Hydrological drought severity explained by climate and catchment characteristics," Journal of Hydrology, vol. 526, pp. 3-14, 2015.

[15] S. M. Vicente-Serrano and J. I. López-Moreno, "Hydrological response to different time scales of climatological drought: an evaluation of the Standardized Precipitation Index in a mountainous Mediterranean basin," Hydrology and Earth System Sciences, vol. 9, no. 5, pp. 523-533, 2005.

[16] A. F. Van Loon, H. A. J. Van Lanen, L. M. Tallaksen et al., "Propagation of drought through the hydrological cycle," WATCH Technical Report 32, 2011.

[17] A. F. Van Loon and H. A. J. Van Lanen, "A process-based typology of hydrological drought," Hydrology and Earth System Sciences, vol. 16, no. 7, pp. 1915-1946, 2012.

[18] K. Haslinger, D. Koffler, W. Schöner, and G. Laaha, "Exploring the link between meteorological drought and streamflow: effects of climate-catchment interaction," Water Resources Research, vol. 50, no. 3, pp. 2468-2487, 2014.

[19] J. Niu, J. Chen, and L. Sun, "Exploration of drought evolution using numerical simulations over the Xijiang (West River) basin in South China," Journal of Hydrology, vol. 526, pp. 68-77, 2015.

[20] S. Huang, Q. Huang, J. Chang, G. Leng, and L. Xing, "The response of agricultural drought to meteorological drought and the influencing factors: a case study in the Wei River Basin, China," Agricultural Water Management, vol. 159, pp. 45-54, 2015.

[21] L. J. Barker, J. Hannaford, A. Chiverton, and C. Svensson, "From meteorological to hydrological drought using standardised indicators," Hydrology and Earth System Sciences, vol. 12, no. 12, pp. 12827-12875, 2015.

[22] J. I. López-Moreno, S. M. Vicente-Serrano, S. Begueria, J. M. Garcia-Ruiz, M. M. Portela, and A. B. Almeida, "Dam effects on droughts magnitude and duration in a transboundary basin: the lower river tagus, pain and Portugal," Water Resources Research, vol. 45, no. 2, Article ID W02405, 2009.

[23] L. Wen, K. Rogers, J. Ling, and N. Saintilan, "The impacts of river regulation and water diversion on the hydrological drought characteristics in the Lower Murrumbidgee River, Australia," Journal of Hydrology, vol. 405, no. 3-4, pp. 382-391, 2011.

[24] C. M. G. Gómez and C. D. P. Blanco, "Do drought management plans reduce drought risk? A risk assessment model for a Mediterranean river basin," Ecological Economics, vol. 76, pp. 42-48, 2012.

[25] R. Zhang, X. Chen, Z. Zhang, and P. Shi, "Evolution of hydrological drought under the regulation of two reservoirs in the headwater basin of the Huaihe River, China," Stochastic Environmental Research and Risk Assessment, vol. 29, no. 2, pp. 487-499, 2014.

[26] A. C. Tyagi, "Developing management strategies for coping with drought," Irrigation and Drainage, vol. 63, no. 2, pp. 271-272, 2014.

[27] P. J. O’Farrell, P. M. L. Anderson, S. J. Milton, and W. R. J. Dean, "Human response and adaptation to drought in the arid zone: lessons from southern Africa," South African Journal of Science, vol. 105, no. 1-2, pp. 34-39, 2009.

[28] J. Christian-Smith, M. C. Levy, and P. H. Gleick, "Maladaptation to drought: a case report from California, USA," Sustainability Science, vol. 10, no. 3, pp. 491-501, 2015.

[29] X. Cai, R. Zeng, W. H. Kang, J. Song, and A. J. Valocchi, "Strategic planning for drought mitigation under climate change," Journal of Water Resources Planning and Management, vol. 141, no. 9, Article ID 04015004, 2015.

[30] T. B. McKee, N. J. Doesken, and K. John, "The relationship of drought frequency and duration to time scales," in Proceedings of the 8th Conference on Applied Climatology, American Meteorological Society, Anaheim, Calif, USA, January 1993.

[31] Q. Mu, M. Zhao, J. S. Kimball, N. G. McDowell, and S. W. Running, "A remotely sensed global terrestrial drought severity index," Bulletin of the American Meteorological Society, vol. 94, no. 1, pp. 83-98, 2013.

[32] Z. C. Hao and A. AghaKouchak, "Multivariate standardized drought index: a parametric multi-index model," Advances in Water Resources, vol. 57, pp. 12-18, 2013.

[33] B. Narasimhan and R. Srinivasan, "Development and evaluation of Soil Moisture Deficit Index (SMDI) and Evapotranspiration Deficit Index (ETDI) for agricultural drought monitoring," Agricultural and Forest Meteorology, vol. 133, no. 1-4, pp. 69-88, 2005.

[34] C. Cammalleri, F. Micale, and J. Vogt, "On the value of combining different modelled soil moisture products for European drought monitoring," Journal of Hydrology, vol. 525, pp. 547558, 2015.

[35] M. C. Anderson, C. hain, J. Otkin et al., "An intercomparison of drought indicators based on thermal remote sensing and 
NLDAS-2 simulations with U.S. drought monitor classifications," Journal of Hydrometeorology, vol. 14, no. 4, pp. 1035-1056, 2013.

[36] World Meteorological Organization, "Drought monitoring and early warning: concepts, progress and future challenges," WMO 1006, World Meteorological Organization, 2006.

[37] M. Svoboda, D. LeComte, M. Hayes et al., "The drought monitor," Bulletin of the American Meteorological Society, vol. 83, no. 8, pp. 1181-1190, 2002.

[38] J. A. Keyantash and J. A. Dracup, "An aggregate drought index: assessing drought severity based on fluctuations in the hydrologic cycle and surface water storage," Water Resources Research, vol. 40, no. 9, Article ID W09304, 2004.

[39] J. F. Brown, B. D. Wardlow, T. Tadesse, M. J. Hayes, and B. C. Reed, "The Vegetation Drought Response Index (VegDRI): a new integrated approach for monitoring drought stress in vegetation," GIScience \& Remote Sensing, vol. 45, no. 1, pp. 1646, 2008.

[40] G. Sepulcre-Canto, S. M. A. F. Horion, A. Singleton, H. Carrao, and J. Vogt, "Development of a Combined Drought Indicator to detect agricultural drought in Europe," Natural Hazards and Earth System Science, vol. 12, no. 11, pp. 3519-3531, 2012.

[41] Z. Hao and V. P. Singh, "Drought characterization from a multivariate perspective: a review," Journal of Hydrology, vol. 527, pp. 668-678, 2015.

[42] P. Patel, "Predicting the future of drought prediction," IEEE Spectrum, vol. 49, no. 9, pp. 18-22, 2012.

[43] X. Yuan, E. F. Wood, N. W. Chaney et al., "Probabilistic seasonal forecasting of African drought by dynamical models," Journal of Hydrometeorology, vol. 14, no. 6, pp. 1706-1720, 2013.

[44] A. Ceppi, G. Ravazzani, C. Corbari, R. Salerno, S. Meucci, and M. Mancini, "Real-time drought forecasting system for irrigation management," Hydrology and Earth System Sciences, vol. 18, no. 9, pp. 3353-3366, 2014.

[45] G. Forzieri, L. Feyen, R. Rojas, M. Flörke, F. Wimmer, and A. Bianchi, "Ensemble projections of future streamflow droughts in Europe," Hydrology and Earth System Sciences, vol. 18, no. 1, pp. 85-108, 2014. 

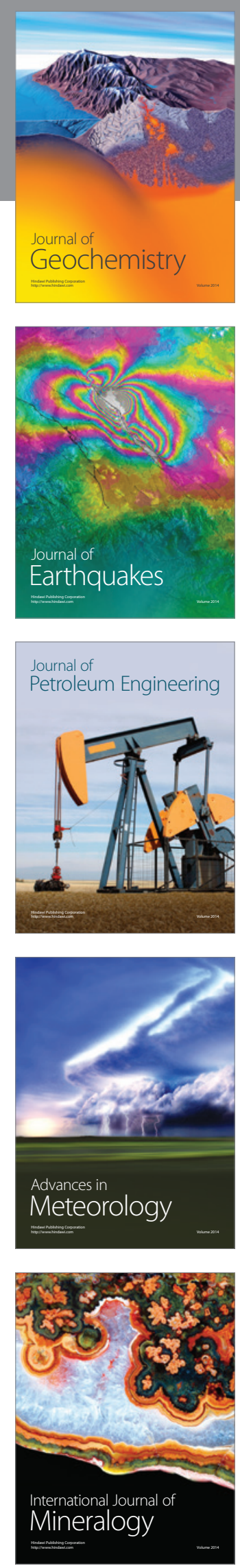
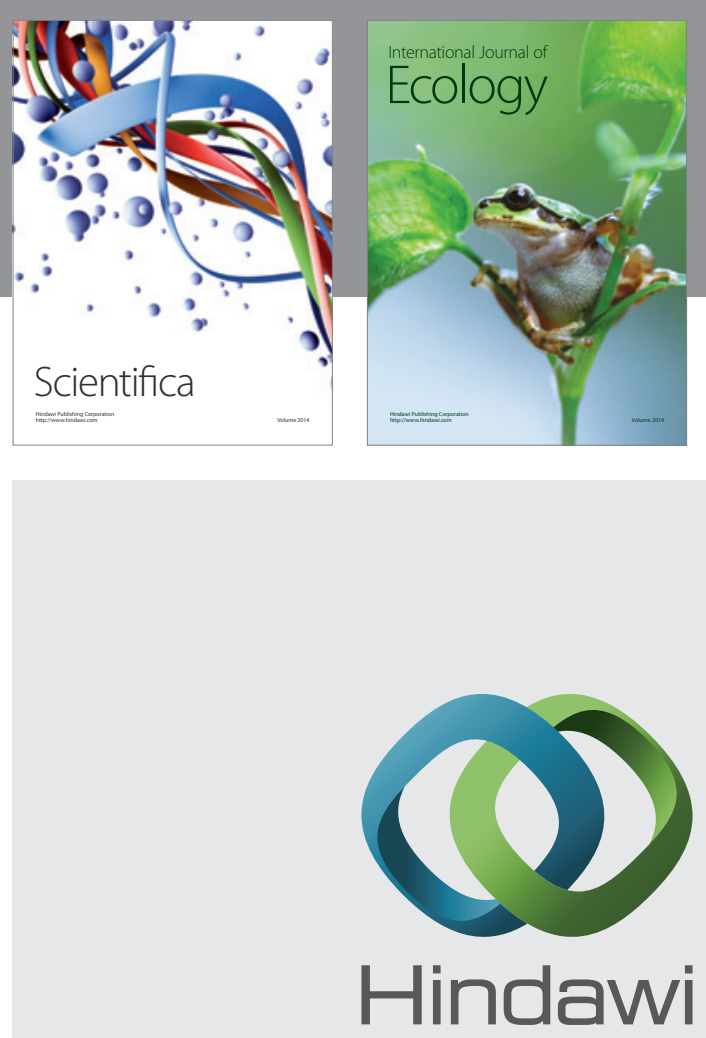

Submit your manuscripts at

http://www.hindawi.com
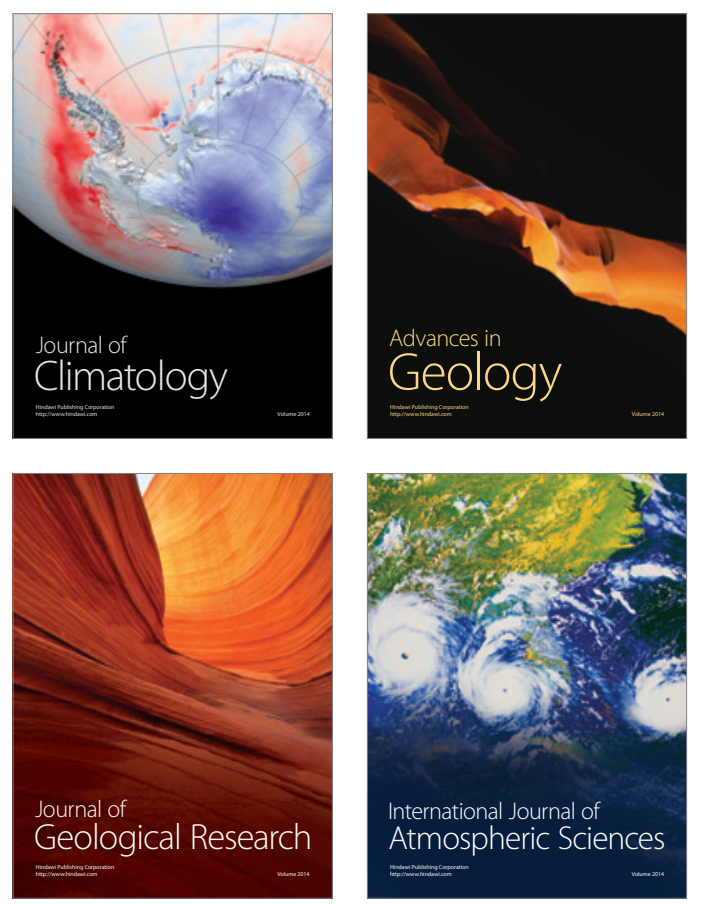

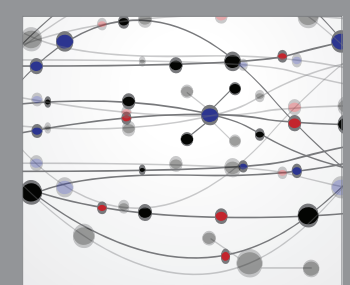

The Scientific

\section{World Journal}
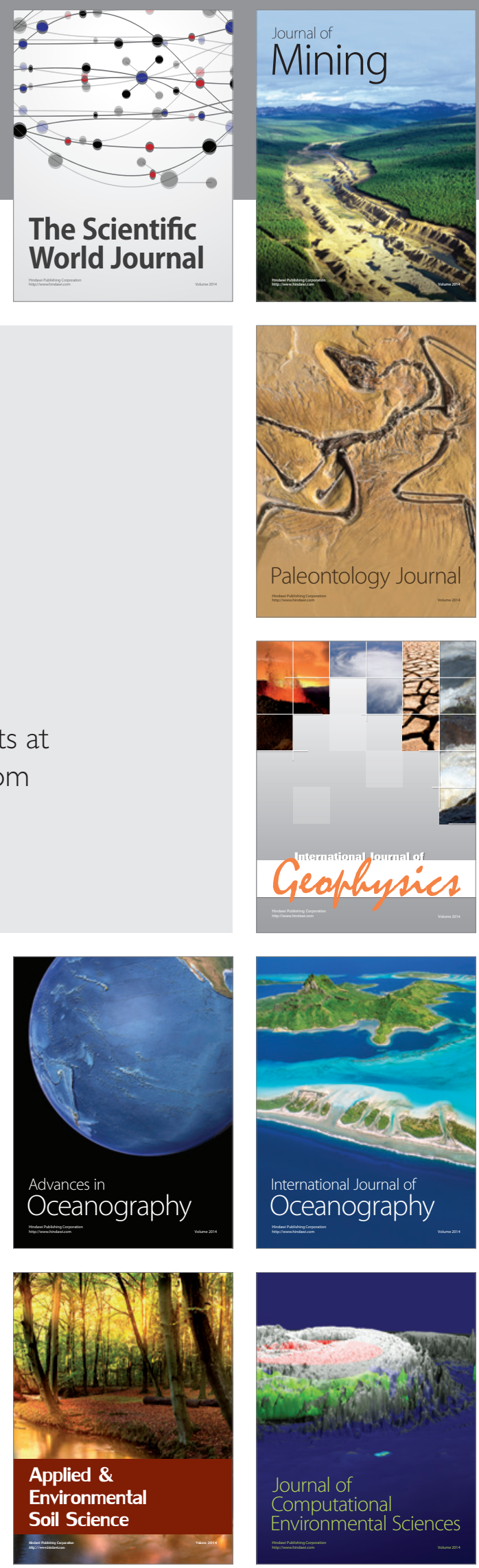